\section{A Fluorinated Cobalt(III) Porphyrin Complex for Hydroalkoxylation of Alkynes}

\author{
Richiro Ushimaru, ${ }^{a}$ Takuho Nishimura, ${ }^{a}$ \\ Toshiki Iwatsuki, ${ }^{a}$ and Hiroshi Naka*,a,b
}

${ }^{a}$ Department of Chemistry, Graduate School of Science, Nagoya University; Chikusa-ku, Nagoya 464-8602, Japan: and ${ }^{b}$ Research Center for Materials Science, Nagoya University; Chikusa-ku, Nagoya 464-8602, Japan.

Received July 13, 2017; accepted August 28, 2017

A fluorinated cobalt(III) porphyrin complex [Co(TPFPP)-

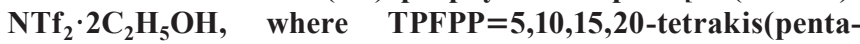
fluorophenyl)porphyrin, $\mathrm{Tf}=\mathrm{CF}_{3} \mathrm{SO}_{2}$ ] promotes hydroalkoxylation of alkynes to give acetals in good to excellent yields. The acetals can be directly functionalized with nucleophiles in a one-pot procedure.

Key words hydroalkoxylation; acetal; alkyne; alcohol; cobalt; porphyrin

Acetals are synthetic equivalents of carbonyl compounds, reacting with various carbon and heteroatom nucleophiles, and are widely used as synthetic intermediates in medicinal chemistry and materials science. ${ }^{1)}$ We here report that a fluorinated $\mathrm{Co}^{\mathrm{III}}$ porphyrin complex, $\mathrm{Co}(\mathrm{TPFPP}) \mathrm{NTf}_{2} \cdot 2 \mathrm{C}_{2} \mathrm{H}_{5} \mathrm{OH}$ [1a, TPFPP =5,10,15,20-tetrakis(pentafluorophenyl)porphyrin, $\left.\mathrm{Tf}=\mathrm{CF}_{3} \mathrm{SO}_{2}\right]^{2)}$ catalyzes Markovnikov hydroalkoxylation of terminal alkynes to acetals ${ }^{3-5}$ ) (Fig. 1). This method compares well with the earlier procedures catalyzed by $\mathrm{Hg}^{6,7)} \mathrm{Pd},{ }^{8-10)}$ $\mathrm{Pt},{ }^{9,11,12)} \mathrm{Au},{ }^{13-22)} \mathrm{Ir}^{23-26)}$ and $\mathrm{Zn}^{27)}$

The active pentafluorophenylated $\mathrm{Co}^{\mathrm{III}}$ catalyst 1a was developed by structural modification of $\mathbf{1 b}$ used previously for alkyne hydration ${ }^{2)}$ (Fig. 1). Reaction of tetrakis(pentafluorophenyl)porphyrin ( $\mathrm{H}_{2}$ TPFPP) and cobalt(II) acetate ${ }^{28)}$ followed by aerobic oxidation in the presence of $\mathrm{HNTf}_{2}$ and recrystallization from a mixture of chloroform, ethanol, and hexane afforded 1a in 67\% yield. X-Ray structural analysis of 1a indicated that (1) the cobalt center adopts octahedral geometry, with porphyrin ligand in the equatorial positions and ethanol in the apical positions (Fig. 2); (2) the counter anion, $\mathrm{Tf}_{2} \mathrm{~N}^{-}$, is spatially separated from the cobalt center [Figure $\mathrm{S} 2(\mathrm{~b})]$. The bound ethanol molecules were labile in $\mathrm{CD}_{3} \mathrm{OD}$

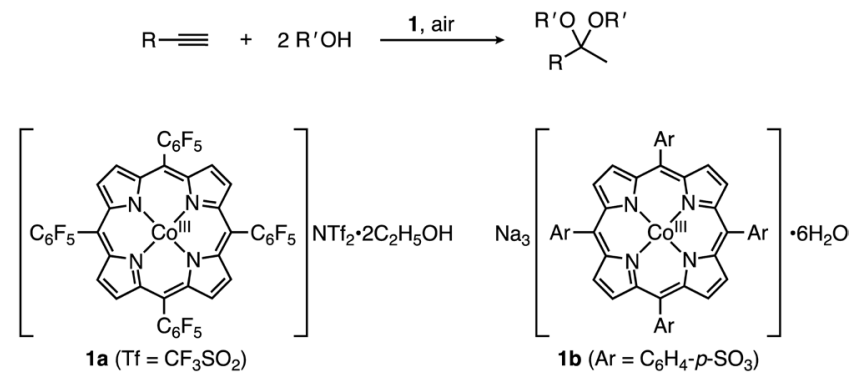

Fig. 1. Hydroalkoxylation of Alkynes Catalyzed by Porphyrin Cobalt(III) Complexes 1 and free ethanol molecules were observed in the ${ }^{1} \mathrm{H}-\mathrm{NMR}$ spectrum [Figure S1(a)].

The catalyst 1a was found to be more reactive than $\mathbf{1 b}$ in the hydroalkoxylation of phenylacetylene (2a) with methanol (Table 1 , entries 1 vs. 7). When a mixture of $\mathbf{2 a}(2.0 \mathrm{mmol})$, 1a $(0.05 \mathrm{~mol} \%)$, and $\operatorname{HNTf}_{2}(0.18 \mathrm{~mol} \%)$ in methanol $(0.9 \mathrm{~mL}$, 11 equiv) was heated at $70^{\circ} \mathrm{C}$ for $4 \mathrm{~h}$ under aerobic conditions, acetal 3a was obtained in $97 \%$ yield (entry 1). ${ }^{29)}$ The initial turnover frequency (TOF) was $4000 \mathrm{~h}^{-1}(t=12 \mathrm{~min})$. This value is comparable to those of gold catalysts and higher than those of catalysts based on other metals (entry 2). ${ }^{30)}$ Hydroalkoxylation of $\mathbf{2 a}$ in the absence of $\mathrm{HNTf}_{2}$ required higher catalyst loading (entries 3 and 4). The reaction proceeded under $\mathrm{N}_{2}$ atmosphere, but yielded 3a in a lower yield than that under air (entry 5 vs. entry 1). Double hydroalkoxylation of $2 \mathbf{a}$ at $27^{\circ} \mathrm{C}$ (room temperature) afforded acetal 3a in 97\% yield (entry 6). $\mathrm{Co}^{\mathrm{III}} \mathrm{TPPCl}[\mathrm{TPP}=5,10,15,20$-tetrakis(phenyl)porphyrin $]$ was less reactive than $\mathbf{1 a}$ and $\mathbf{1 b}$ (entry $8 v$ s. entries 1 and 7). The reaction hardly proceeded with analogous metal complexes such as $\mathrm{Fe}^{\mathrm{III}} \mathrm{TPPCl}$ or $\mathrm{Mn}^{\mathrm{III}} \mathrm{TPPCl}$ under otherwise identical conditions (entries 9 and 10).

(a)

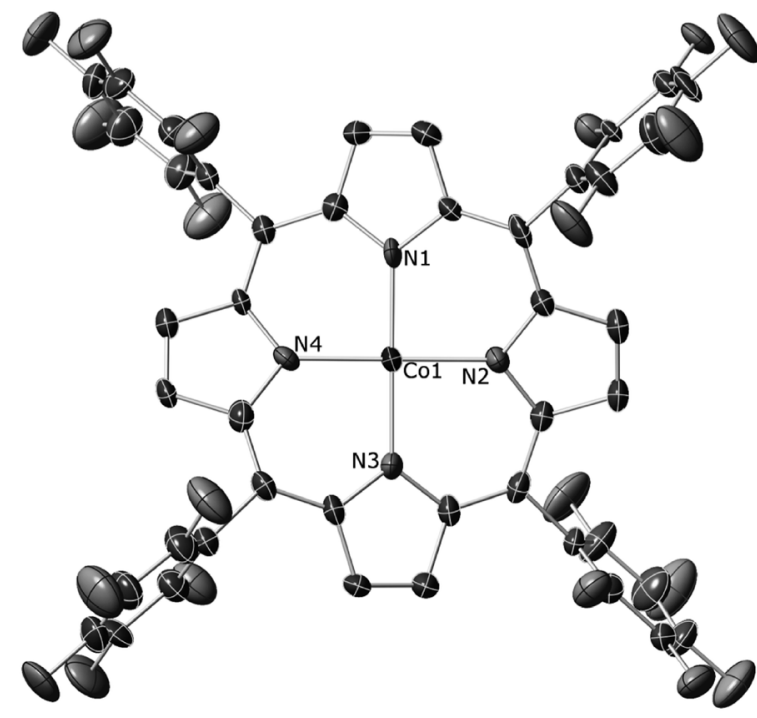

(b)

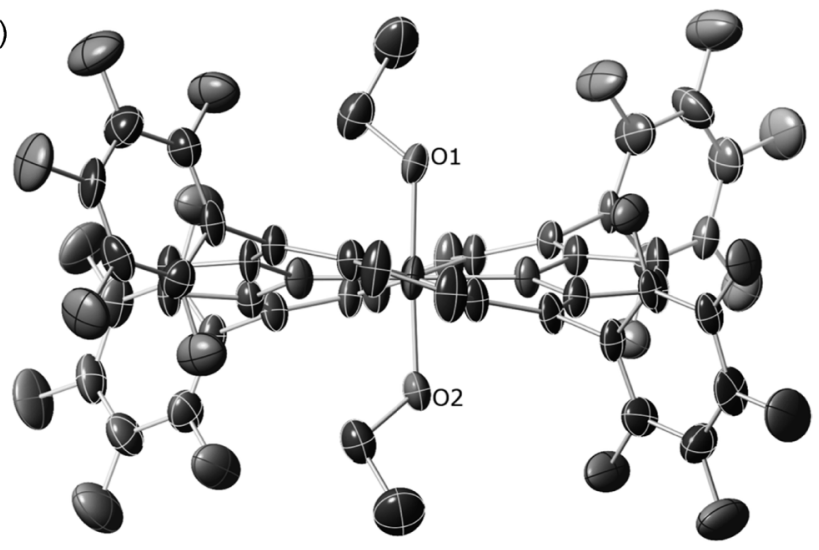

Fig. 2. ORTEP Drawing of 1a: (a) Top View and (b) Side View

Thermal ellipsoids are drawn at 50\% probability. Coordinated ethanol molecules in (a) as well as the counter anion and hydrogen atoms in (a) and (b) are omitted for clarity. 
Table 1. Double Hydromethoxylation of Alkynes with Methanol ${ }^{a}$

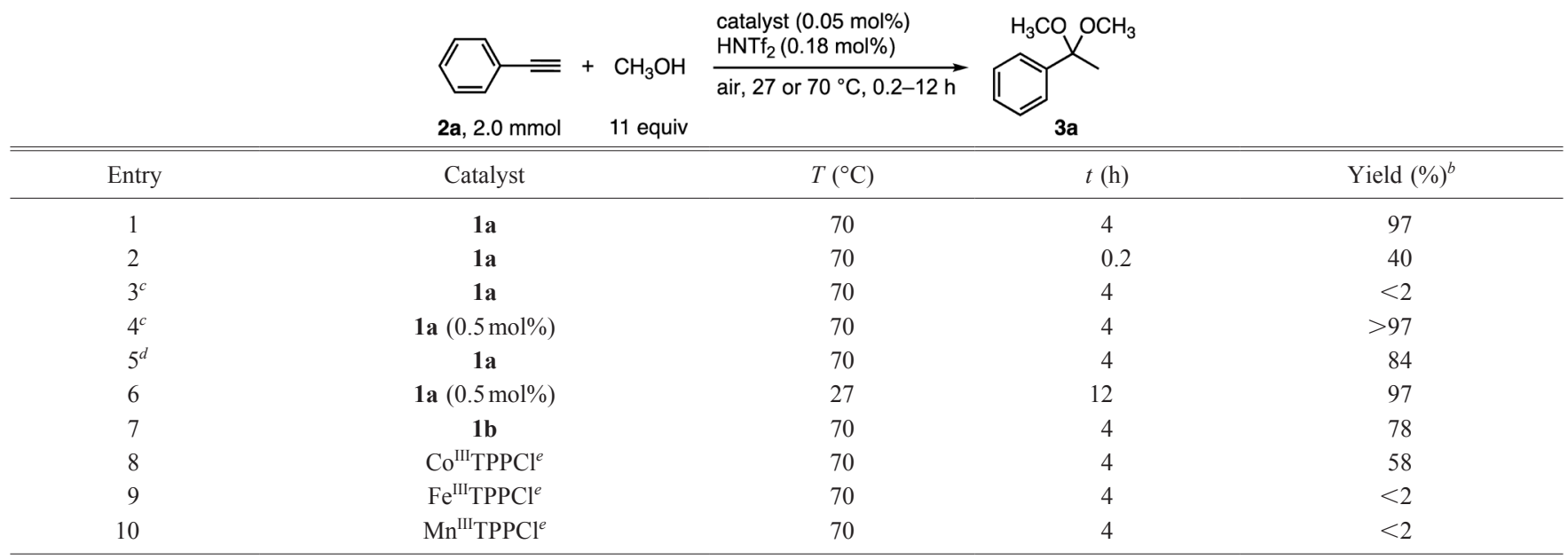

${ }^{a}$ Conditions: 2a $(2.0 \mathrm{mmol})$, catalyst $(0.05 \mathrm{~mol} \%), \mathrm{HNTf}_{2}(0.18 \mathrm{~mol} \%), \mathrm{CH}_{3} \mathrm{OH}\left(0.9 \mathrm{~mL}, 11\right.$ equiv) under aerobic conditions in a closed reaction vessel. ${ }^{b}$ Determined by ${ }^{1} \mathrm{H}-\mathrm{NMR}$ using mesitylene as an internal standard. ${ }^{c}$ In the absence of $\mathrm{HNTf}_{2} .{ }^{d}$ Under $\mathrm{N}_{2}$ atmosphere. ${ }^{e} \mathrm{TPP}=$ tetrakis(phenyl)porphyrin.

Table 2. Double Hydromethoxylation of Alkynes Using Co (TPFPP) $\mathrm{NTf}_{2} \cdot 2 \mathrm{C}_{2} \mathrm{H}_{5} \mathrm{OH}$ Complex (1a) ${ }^{a}$

\begin{tabular}{|c|c|c|c|c|c|c|}
\hline \multicolumn{2}{|c|}{$\begin{array}{c}\mathrm{R}= \\
2,10 \mathrm{mmol}\end{array}$} & $\begin{array}{l}\mathrm{CH}_{3} \mathrm{OH} \\
11 \text { equiv }\end{array}$ & \multicolumn{2}{|c|}{$\begin{array}{l}\text { 1a }(0.05-0.5 \mathrm{~mol} \%) \\
\mathrm{HNTf}_{2}(0.18 \mathrm{~mol} \%)\end{array}$} & \multicolumn{2}{|c|}{$\mathrm{H}_{3} \mathrm{CO} V^{\mathrm{OCH}_{3}}$} \\
\hline Entry & 2 & Acetal (3) & & $1 \mathrm{a}\left(\mathrm{mol}^{\circ} \%\right)$ & $t(\mathrm{~h})$ & Yield $(\%)^{b}$ \\
\hline 1 & $2 a$ & & 3a & 0.05 & 12 & 94 \\
\hline $2^{c, d}$ & $2 a$ & & $3 a b$ & 0.13 & 16 & 67 \\
\hline $3^{c, d}$ & $2 a$ & & $3 a c$ & 0.30 & 16 & 59 \\
\hline 4 & $2 b$ & & $3 \mathbf{b}$ & 0.05 & 12 & 82 \\
\hline 5 & $2 c$ & & $3 c$ & 0.50 & 12 & 96 \\
\hline $6^{e}$ & $2 d$ & & $3 d$ & 0.05 & 24 & 83 \\
\hline 7 & $2 e$ & & $3 e$ & 0.25 & 12 & 86 \\
\hline $8^{c}$ & $2 f$ & & $\mathbf{3 f}$ & 0.25 & 24 & 76 \\
\hline
\end{tabular}

${ }^{a}$ Conditions: 2 (10 mmol), 1a $(0.05 \mathrm{~mol} \%), \mathrm{CH}_{3} \mathrm{OH}\left(4.5 \mathrm{~mL}, 11\right.$ equiv), $\mathrm{HNTf}_{2}(0.18 \mathrm{~mol} \%)$ at $70^{\circ} \mathrm{C}$ under aerobic conditions in a closed reaction vessel. ${ }^{b}$ Isolated yield. ${ }^{c}$ In the absence of $\mathrm{HNTf}_{2}, 50^{\circ} \mathrm{C}$. ${ }^{d}$ Ethanol $(4.5 \mathrm{~mL}, 7.7$ equiv, entry 2$)$ or allyl alcohol $(4.5 \mathrm{~mL}, 6.6$ equiv, entry 3$)$

was used instead of methanol. ${ }^{e} 20 \mathrm{mmol}$ scale.

Other examples of this transformation are listed in Table 2. Reaction of $\mathbf{2 a}(10 \mathrm{mmol})$ with methanol in the presence of 1a $(0.05 \mathrm{~mol} \%)$ and $\mathrm{HNTf}_{2}(0.18 \mathrm{~mol} \%)$ at $70^{\circ} \mathrm{C}$ for $12 \mathrm{~h}$ under aerobic conditions gave the corresponding acetal $\mathbf{3 a}$ in $94 \%$ isolated yield after distillation (Table 2, entry 1). Double hydroalkoxylation of $\mathbf{2 a}$ using ethanol and allyl alcohol gave the corresponding acetals in acceptable yields (entries 2 and 3). Reactions using 2-propanol and tert-butyl alcohol were slug- 


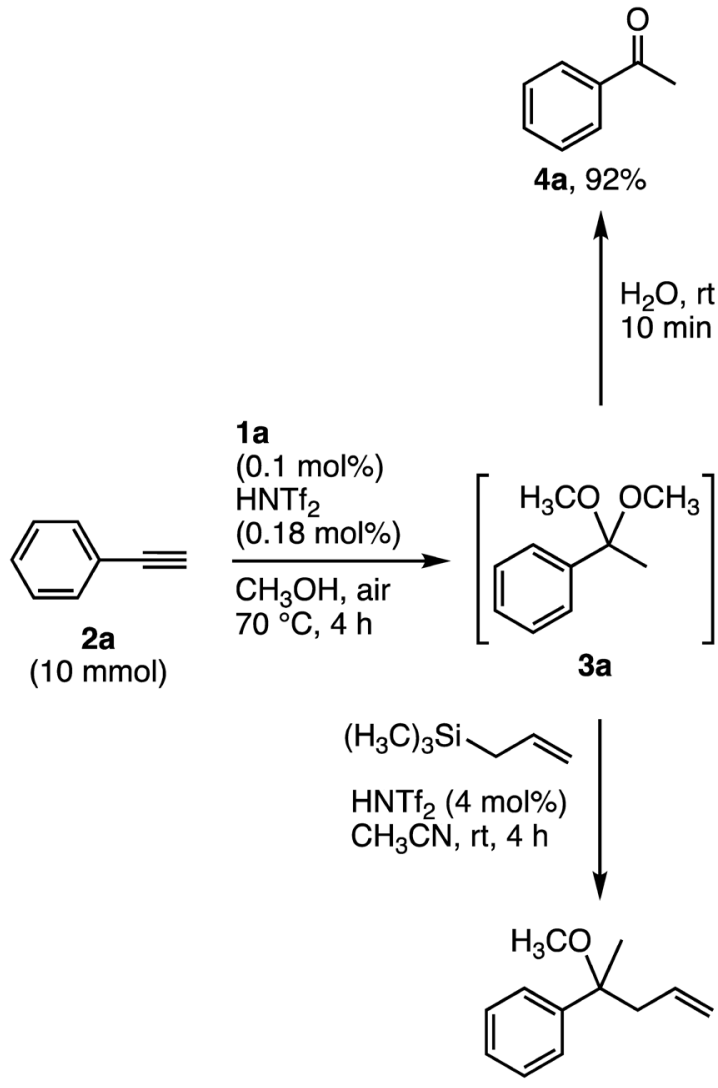

8 a, $70 \%$

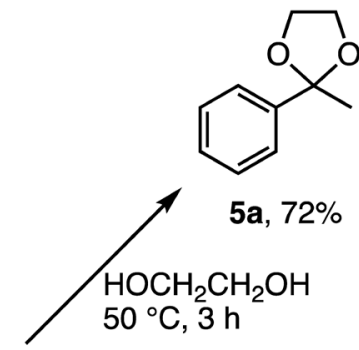

$6 a, 76 \%$

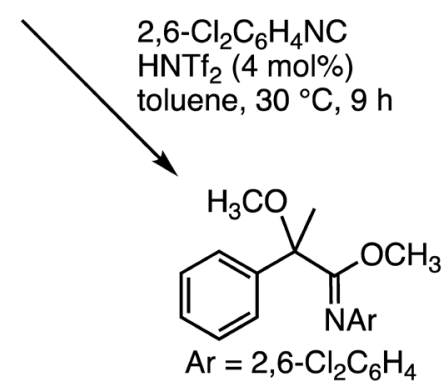

$7 a, 65 \%$

Chart 1.

gish. $t$-Butyl-substituted phenyl acetylene $\mathbf{2 b}$ was as reactive as 2a (entry 4). Although trifluoromethyl analogue 2c was less reactive, complete conversion was obtained at $12 \mathrm{~h}$ with the use of $0.5 \mathrm{~mol} \%$ of catalyst 1a (entry 5). This method was also effective for aliphatic alkynes 2d-f (entries 6-8). Double hydroalkoxylation of $\mathbf{2} \mathbf{f}$ in the absence of $\mathrm{HNTf}_{2}$ proceeded without destruction of the cyclopropyl moiety in $\mathbf{2 f}$. Unfortunately, the present method was not effective for internal alkynes (e.g. diphenylacetylene) or propargylic substrates (e.g. propargyl alcohol), as is also the case for alkyne hydration catalyzed by $\mathbf{1 b}$. $^{2}$

Next, because acetals are reactive electrophiles, ${ }^{31-34)}$ one-pot conversion of in-situ-generated acetal 3a with nucleophiles was examined (Chart 1). Double hydroalkoxylation of alkyne 2a with methanol using 1a $(0.1 \mathrm{~mol} \%)$ in the presence of $\mathrm{HNTf}_{2}(0.18 \mathrm{~mol} \%)$, followed by trapping of acetal 3a with water, ethylene glycol, and aniline, gave the corresponding ketone $\mathbf{4 a}$, cyclic acetal $\mathbf{5 a}$ and imine $\mathbf{6} \mathbf{a}$, respectively, in good yields. This stepwise protocol gave better results than the direct addition of these nucleophiles to $\mathbf{2 a}$. Insertion of arylisonitrile into the $\mathrm{C}-\mathrm{O}$ linkage of $\mathbf{3 a}$ gave $\alpha$-methoxyimidate 7a. ${ }^{35)}$ Analogously, Hosomi-Sakurai reaction of acetal 3a with allyltrimethylsilane afforded ether $\mathbf{8} \mathbf{a}^{36,37)}$ Overall, the present method allowed direct conversion of alkyne to a variety of substituted Markovnikov-type products, using methanol and nucleophiles.

In summary, the cationic cobalt porphyrin complex 1a was found to catalyze hydroalkoxylation of terminal alkynes to acetals under slightly acidic, aerobic conditions. The acetal intermediates can be directly functionalized with nucleophiles.
Acknowledgments This work was supported by the Japan Society for the Promotion of Science (JSPS) KAKENHI Grant Number JP23750109 (to H.N.) and JP15KT0141 (to H.N.)]. The authors would like to thank Professor Ryoji Noyori (Nagoya University) for his insightful comments, and extend their gratitude to Hiroyuki Okabe and Tomomi Banno (Nagoya University) for their technical assistance.

Conflict of Interest The authors declare no conflict of interest.

Supplementary Materials The online version of this article contains supplementary materials: experimental procedures and characterization of $\mathbf{1 a}$.

\section{References and Notes}

1) von Angerer S., Warriner S. L., "Science of Synthesis," Vol. 29, ed. by Warriner S. L., Thieme, Stuttgart, 2007, pp. 303-406.

2) For hydration of terminal alkynes with a water-soluble $\mathrm{Co}^{\mathrm{III}}$ porphyrin complex, see: Tachinami T., Nishimura T., Ushimaru R., Noyori R., Naka H., J. Am. Chem. Soc., 135, 50-53 (2013).

3) Hintermann L., Labonne A., Synthesis, 1121-1150 (2007).

4) Alonso F., Beletskaya I. P., Yus M., Chem. Rev., 104, 3079-3159 (2004)

5) Goodwin J. A., Aponick A., Chem. Commun., 51, 8730-8741 (2015).

6) Reichert J. S., Bailey J. H., Nieuwland J. A., J. Am. Chem. Soc., 45, 1552-1557 (1923).

7) Nieuwland J. A., Vogt R. R., Foohey W. L., J. Am. Chem. Soc., 52, 1018-1024 (1930).

8) Utimoto K., Pure Appl. Chem., 55, 1845-1852 (1983). 
9) Steinborn D., Nünthel R., Krause K., J. Organomet. Chem., 414, C54-C58 (1991)

10) Scheffknecht C., Peringer P., J. Organomet. Chem., 535, 77-79 (1997).

11) Kataoka Y., Matsumoto O., Tani K., Organometallics, 15, 52465249 (1996).

12) Hartman J. W., Sperry L., Tetrahedron Lett., 45, 3787-3788 (2004).

13) Fukuda Y., Utimoto K., J. Org. Chem., 56, 3729-3731 (1991).

14) Teles J. H., Brode S., Chabanas M., Angew. Chem. Int. Ed., 37, 1415-1418 (1998).

15) Casado R., Contel M., Laguna M., Romero P., Sanz S., J. Am. Chem. Soc., 125, 11925-11935 (2003).

16) Santos L. L., Ruiz V. R., Sabater M. J., Corma A., Tetrahedron, 64, 7902-7909 (2008)

17) Leyva A., Corma A., J. Org. Chem., 74, 2067-2074 (2009).

18) Corma A., Ruiz V. R., Leyva-Perez A., Sabater M. J., Adv. Synth. Catal., 352, 1701-1710 (2010).

19) Kuram M. R., Bhanuchandra M., Sahoo A. K., J. Org. Chem., 75, 2247-2258 (2010).

20) Bouhrara M., Jeanneau E., Veyre L., Copéret C., Thieuleux C., Dalton Trans., 40, 2995-2999 (2011).

21) Oonishi Y., Gomez-Suarez A., Martin A. R., Nolan S. P., Angew. Chem. Int. Ed., 52, 9767-9771 (2013).

22) Miura Y., Mochida T., Motodate S., Kato K., Polyhedron, 113, 1-4 (2016).

23) Masui D., Ishii Y., Hidai M., Chem. Lett., 27, 717-718 (1998).
24) Hirabayashi T., Okimoto Y., Saito A., Morita M., Sakaguchi S., Ishii Y., Tetrahedron, 62, 2231-2234 (2006).

25) Konkol M., Schmidt H., Steinborn D., J. Mol. Catal. A, 269, 119124 (2007).

26) Konkol M., Schmidt H., Steinborn D., J. Mol. Catal. A, 261, 301305 (2007).

27) Breuer K., Teles J. H., Demuth D., Hibst H., Schafer A., Brode S., Domgorgen H., Angew. Chem. Int. Ed., 38, 1401-1405 (1999).

28) Kadish K. M., Araullo-McAdams C., Han B. C., Franzen M. M., J. Am. Chem. Soc., 112, 8364-8368 (1990).

29) $\overline{\mathrm{HNTf}}_{2}$ was selected because it accelerated the alkyne hydration. ${ }^{2)}$

30) Turnover frequencies (TOFs; $h^{-1}$ ) of typical catalysts for hydroalkoxylation of alkynes are: $c a .5400(\mathrm{Au})^{14)} ; c a .294000(\mathrm{Au})^{20)} ; c a .39$ $(\mathrm{Au})^{22)} ; c a .8(\mathrm{Pt})^{12)} ; c a .7$ (Ir). ${ }^{25)}$

31) Mukaiyama T., Murakami M., Synthesis, 1043-1054 (1987).

32) Alexakis A., Mangeney P., Tetrahedron Asymmetry, 1, 477-511 (1990).

33) Murata S., Suzuki M., Noyori R., J. Am. Chem. Soc., 102, $3248-$ $3249(1980)$

34) Noyori R., Murata S., Suzuki M., Tetrahedron, 37, 3899-3910 (1981).

35) Tobisu M., Kitajima A., Yoshioka S., Hyodo I., Oshita M., Chatani N., J. Am. Chem. Soc., 129, 11431-11437 (2007).

36) Kampen D., List B., Synlett, 16, 2589-2592 (2006).

37) Berbero M., Bazzi S., Cadamuro S., Dughera S., Piccinini C., Synthesis, 2, 315-319 (2010). 